\title{
Loose talk: psychiatrists, the media and ethics*
}

\author{
Philip Timms
}

"Prince was far too stressed out to fly says royal shrink ... Bungling Prince Charles was lashed by a top psychiatrist last night" (Airs, 1994). This colourful fragment from a national tabloid illustrates one of the less savoury aspects of the increasing visibility of psychiatry in the media. The College Public Education Committee (PEC) was established in 1988 and has monitored press references to the College. In the three years prior to its establishment, it was able to find only seven press references to the College. A more recent survey, from September 1992-1993, found 736 such references (D. Hart, Royal College of Psychiatrists, personal communication). This dramatic increase has been partly due to the increasing politicisation of health care in general. However, a significant role has been played by the PEC. It has established an efficient machine which not only disseminates information from the College to the media, but also responds to inquiries from the media. On the whole, the results of this sort of activity are beneficial, the main complication being that of misrepresentation. We tend to be painfully aware of the dubious practices of the media, in particular the iniquities of the tabloid press. However, we also need to consider the possible ethical blunders that we may commit. The whole enterprise of speaking or writing about psychiatry in the public arena has generated several areas of ethical concern.

\section{The right to talk about an individual Confidentiality}

The right to privacy, particularly the kind of confidentiality generated by the doctor/patient relationship, conflicts with the public's right to know. This tension was acknowledged in advice given to hospitals by the Department of Health and Social Security in 1956 (Ministry of Health. 1956):

This paper is based on a presentation given at the Regional Public Education Officers' day at the College on 25 November 1994.
Hospitals will be fully aware of the importance of preserving the confidential relationship between themselves and their patients; but Boards and Committees will no doubt also recognise the reasonable desire of the press to be provided with information in cases of public interest.

If we are party to information gained as part of our clinical involvement with a patient, the only way in which we can justifiably discuss it in the public arena is with the permission of the patient concerned. The issue of informed consent may be difficult to resolve if a patient's mental state is significantly impaired. This will often be the case when public interest is aroused, particularly by incidents involving violence or injury.

\section{Speculation}

The quote at the beginning of this work represents a typical piece of tabloid psychiatric speculation and, incidentally, illustrates the danger of becoming a player in the royal soap opera. Many instances of this sort are actually not the fault of the psychiatrist involved. They may not even be the fault of the journalist who did the original interview, which may have been a sober, technical discussion about general aspects of a disorder. The end result may well be an imaginative interpretation generated from a sub-editor's desk. However, it is likewise not always the media's fault. The American Psychiatric Association (1982) guidelines suggest that:

On occasion psychiatrists are asked for an opinion about an individual who is in the light of public attention or who has disclosed information about himself through public media. It is unethical for a psychiatrist to offer a professional opinion unless he/ she has conducted an examination and has been granted proper authorisation for such a statement.

This expresses a view that I believe is reasonable and widely held, if rarely explicitly expressed. Our ability to comment professionally on an individual stems solely from our having met them and talked with them. Only then can we come to an informed judgement about them. But is there any harm in speculation about a person we have never met? I believe there is. Given our lack of first hand knowledge about a person it is both presumptuous and impertinent, at best 
a glaring discourtesy. It suggests that we have the ability to read minds, a commonly-held and unhelpful misconception which needs no further reinforcement from ourselves. Moreover, by pretending to knowledge we don't have, we are as likely to be wrong as to be right. We thereby lay open ourselves and our profession to quite justifiable censure and ridicule.

\section{Broadcast consultations}

Live phone-in shows have been the great success story of American radio in the last two decades (Klonoff, 1983) and are now common in the UK. And where people talk about their problems, you'll invariably find a psychiatrist or psychologist willing to get involved, conducting on-air conversations with callers who will often have significant mental health problems. This activity has even generated its own jargon, becoming known as 'mediated therapeutic communication'. Three issues of concern have arisen.

Exploitation Early American Psychological Association's (1953) guidelines state:

It is unethical to employ psychological techniques for devious purposes, for entertainment, or for other reasons not consonant with the best interest of a client or with the development of psychology as a science.

This makes an apparently clear association between entertainment and exploitation. However, it is now generally accepted that it is possible to be both informative and entertaining. It is clear that if a programme is not entertaining, it will not be broadcast.

Confidentiality Callers obviously know they will be heard on air, often by an audience of millions. Nevertheless, there seems to be no shortage of people willing to bare their souls in this public fashion. The medium creates a paradoxically powerful sense of intimacy, but it may also be that the anonymity of the communication compensates for the lack of apparent confidentiality (Drucker, 1990).

Therapy $v$. education The American Psychological Association's (1981) guidelines for broadcast consultations make a clear distinction between advice and therapy, emphasising academic and clinical standards:

Individual diagnostic and therapeutic services are provided only in the context of a professional psychological relationship. When personal advice is given by means of public lectures or demonstrations. newspaper or magazine articles, radio or television programmes, mail, or similar media, the psychologist utilises the most current relevant data and exercises the highest level or professional judgement.
Those of the American Psychiatric Association (1982) specifically prohibit any communication that might be deemed therapeutic:

It is appropriate for psychiatrists appearing on radio and/or television to provide any advice which could be considered as therapy to a member of the studio or listening audience. Psychiatrists should not attempt to state a diagnosis or, in any conclusive way, describe the problem that may be troubling the person. The psychiatrists may, however, ask the caller questions to obtain additional information that could help in suggesting referrals.

It is assumed that for any meaningful or helpful therapy to take place, the therapist must have a full knowledge of the client's background and problems. Obviously, this is not the case in the arena of the radio phone-in and there are anxieties about the propriety of giving therapy in this context at all. Therapeutic activity might also incur legal liabilities.

Despite the apparently clear differences between giving information, giving advice, and giving treatment, in practice it seems difficult to maintain boundaries. A survey of six American radio shows (Henricks \& Stiles, 1989) examined the ways of talking (Verbal Response Modes, VRMs) of psychological radio hosts and their callers. The VRMs used in these conversations were compared with those occurring in psychotherapy, university settings and medical interviews. It found that radio hosts' VRMs most resembled those of rational-emotive therapists, whereas those of callers most resembled those of clients in cognitive-behavioural therapy. So, however hard they may try, therapists just can't stop being therapists, even before an audience of millions and why not if they are achieving good results, or at least not doing harm? One of the few studies to examine the benefits and possible harm resulting from phone-in consultations (McCall, 1990) conciuded that most callers regarded their experience as having been neutral or beneficial and that there was little evidence of harm.

\section{Advertising}

Even in the USA, where there is a very well developed commercial culture in medicine, selfadvertising in the context of media appearances has been frowned upon (Bohoutsos et al, 1986). In the UK life was relatively straightforward before the 'Balkanisation' of the National Health Service. Public pronouncements could be construed clearly as either educational, and ethical. or as advertising and unethical. Unless one made a blatant plug for referrals that would produce financial benefits, a communication would be construed as educative. Even if a particular service or doctor was thereby differentiated from others, no great benefit would usually accrue to 
the individual or service concerned. In fact the extra referrals and resulting workload might well be regarded as a nuisance rather than as a bonus.

Now things are dramatically different. In the new health marketplace, trusts will seek to secure their niche by promoting service differentiation and a high public profile. However sober and professional, any presentation in this context that differentiates oneself or a service from other services, could be construed as advertising and therefore unethical. Without any change in the form or content of what is being said, the philosopher's stone of the free market has the capacity to transmute the base matter of education into the precious metal of advertising.

\section{"Seeking the bubble reputation" (Shake- speare, As You Like It II, vii, 139)}

Media attention can be immensely flattering (Klonoff, 1983). It is both wise and proper to be aware for whom one is speaking and in what capacity. To lend authority, an introduction may describe you as a leading psychiatrist from a particular institution, or even as a 'top doc'. But are you representing that institution, the College or just yourself? Are you an expert in the particular area under discussion, or are you offering your opinion as a general psychiatrist?

\section{Conclusion}

Psychiatrists should not be discouraged from talking to or writing for the media. If we do not represent our position, then it will be misrepresented by others. Serious consideration of the ethical issues involved is not only proper but also has the potential to render more robust and credible our communications with the public. The College's Special Committee on Unethical Psychiatric Practices has expressed agreement with the American Psychiatric Association's guidelines on statements to the press (Royal College of Psychiatrists, 1992, 1997). However, a re-statement of this position in 1994 suggested that these guidelines had not been rigorously followed (Caldicott, 1994). More recently the College Registrar has highlighted this issue and has emphasised the possible disciplinary consequences of breaching these guidelines (Thompson, 1997). It remains to be seen whether this has an impact, but it is worth emphasising that the Public Education Department is always willing to advise on these matters.

\section{References}

AIRS, K. (1994) Runway Drama. Daily Star. 30 June. 4.

AMERICAN PSYCHIATRIC ASSOCIATION (1982) Addendum to Public Affairs Guidelines, p. 3. Washington. DC: APA.

AMERICAN PSYCHOLOGICAL AsSOCLATION (1953) Ethical Standards of Psychologists. Washington. DC: American Psychological Association.

- (1981) Ethical principles of psychologists. American Psychologist, 36, 633-638.

BoнouTsos, J. C.. GOODCHILDS, J. D. \& HudDY, L. (1986) Media psychology: an empirical study of radio call-in psychology programs. Professional Psychology: Research and Practice, 17, 408-414.

CALDICOTT, F. (1994) Psychiatrists' professional opinions to the press. Psychiatric Bulletin, 18, 441.

DRUCKER. S. J. (1990) Legal and ethical implications of mediated therapeutic communication. In Talking to Strangers: Mediated Therapeutic Communication leds G. Gumpert \& S. L. Fish). pp. 200-213. Norwood: Ablex Publishing.

HENRICKS. W. H. \& STtLES. W. B. (1989) Verbal processes on psychological radio call-in programs: comparisons with other help-intended interactions. Professional Psychology: Research and Practice, 20, 315-321.

KLONOFF, E. A. (1983) A star is born: psychologists and the media. Professional Psychology: Research and Practice. 14, 847-854.

MCCALL. R. B. (1990) Ethical considerations of psychologists working in the media. In Ethics in Applied Developmental Psychology: Emerging Issues in an Emerging Fleld. Annual Aduances in Applied Development Psychology. Vol. 4, (eds C. B. Fisher \& W. W. Tryon), pp. 163-185. Norwood: Ablex Publishing.

MINISTRY OF HEALTH (1956) Information to the Press about the Condition of Patients. HM (56)58. London: Her Majesty's Stationery Office.

Royal College of Psychiatrists (1992) Psychiatrists professional opinions to the press. Psychiatric Bulletin. 16. 458.

- (1997) Psychiatrists professional opinions to the media - revised guidelines. Psychiatric Bulletin. 21. 62.

THOMPSON. P. (1997) Psychiatrists' professional opinions to the media. Psychiatric Bulletin, 21, 62.

Philip Timms, Senior Lecturer in Community Psychiatry, Guy's and St Thomas's UMDS, London 